\title{
THE SOCIETY ESTABLISHES A NEW PERIODICAL
}

Through the munificence of two of the great Foundations, the American Mathematical Society is in the fortunate position of having the financial backing to found a new international mathematical abstracting journal to be known as Mathematical Reviews. During the past quarter-century, while the United States and Canada have been gradually assuming a more prominent part in mathematical research, there has been sentiment expressed from time to time among mathematicians that there should be an abstract journal sponsored by American organizations. But the doubts whether we had the scientific and financial resources to spare caused the postponement of the undertaking. However, the rapid growth of our mathematical resources and the availability of funds have resolved these doubts and it has been decided to proceed immediately.

At the Annual Meeting of 1938 the Council of the Society appointed a committee consisting of C. R. Adams (chairman), G. D. Birkhoff, A. B. Coble, Thornton C. Fry, Marston Morse, and G. T. Whyburn with power to proceed with the establishment of a new journal provided the finances could be assured for a period of five years and provided international coöperation could be obtained. After much correspondence and several meetings and after consulting representative mathematicians in all parts of the country, the Committee decided on May 30, 1939 to proceed; and this decision was later ratified by the Council and by the Board of Trustees. An executive subcommittee consisting of Oswald Veblen (chairman), Thornton C. Fry, and Warren Weaver was appointed to officiate in setting up the machinery to get the journal underway, and this group will function until the Society makes permanent arrangements for the direction of the journal. The Council at the September meeting took initial steps to change the by-laws of the Society so as to define the relationship and responsibility of the Society to the new journal.

It is confidently expected that the assumption of this important task will stimulate research and teaching. Coöperation from the great fraternity of mathematicians is assured. Several hundred people have signed petitions requesting that the journal be inaugurated. Meetings of groups in various parts of the country have been held to discuss the desirability of the project and great interest has been evinced. Prominent mathematicians both here and abroad have given assurances that collaborators will be available in abundant numbers to carry on the journal at a high level. 
The Carnegie Corporation has appropriated $\$ 60,000$ as a backlog for the new journal. The Rockefeller Foundation has made a gift of $\$ 12,000$ to cover some of the initial costs. Brown University is housing the project and aiding in the editorial work. The American Mathematical Society and the Mathematical Association of America are each starting off with a subsidy of $\$ 1,000$ for the first year. Annual subsidies are being sought from other organizations, with prospects of success. Plans for the permanent financing of the project are also being considered.

The first number of Mathematical Reviews is to appear late in 1939 or early in 1940; the material to be reviewed begins with the latter half of 1939. It is proposed to review all fields of pure mathematics and also those parts of applied mathematics and mathematical physics which are of pronounced interest to mathematicians. The new journal, which will be issued approximately once a month, will contain several thousand reviews annually and will run to approximately eight hundred large double-column pages, each page being equivalent to nearly two of this Bulletin. Professors J. D. Tamarkin and O. Neugebauer will be the first editors. A strong group of collaborators for the initial period is assured. No salaries will be paid to the editors.

The languages to be used in the new journal are English, French, German, and Italian. It is planned to print a large edition of the first number and to circulate it among mathematicians throughout the world with a blank form calling for subscriptions. On account of the generous subventions, the price will be set drastically below actual cost. It has been decided to set the price at $\$ 13.00$ with reductions to $\$ 6.50$ for members of the supporting organizations and $\$ 3.25$ to reviewers.

Partly with a view to aiding indirectly in the support of this journal, the Rockefeller Foundation has made a handsome gift to Brown University for an experiment in the dissemination of mathematical publications through the distribution of microfilm. This money is to be used to augment the mathematical library at that University, a collection which is already internationally known as outstanding. Out-of-print journals will be put on film and made available to mathematicians; rare books of general use will be filmed; on request from a subscriber to the new journal, any article reviewed will be sent on film or as film-print. This service will be extended to all parts of the world at a price not exceeding cost. It should be of greatest value to mathematicians located in the smaller universities and colleges and should be a factor in encouraging young men and women 
to continue with their investigations. This interesting experiment in the promotion of a new aid to learning should prove to be an asset not only to Mathematical Reviews, but also to American mathematics in general.

Authors are requested to send reprints or preprints of all their research articles, beginning July 1, 1939, and as soon as they are available, to Mathematical Reviews, American Mathematical Society, Brown University, Providence, R. I. This will aid in getting reviews made promptly. Subscriptions may be sent to the New York office of the Society.

R. G. D. RichaRdSON, Secretary 